\title{
Definições operacionais e análise funcional de termos presentes nas questões do Inventário de Estilos Parentais (IEP)
}

\section{Operational definitions and functional analysis of terms present in the Parental Styles Inventory questions}

\section{Definiciones operacionales y análisis funcional de términos presentes en las preguntas del Inventario de Estilo Parental}

\author{
Amanda Viana dos Santos ${ }^{1}$, Cristiano Coelho²
} [1] [2] Pontifícia Universidade Católica de Goiás I Título abreviado: Operacionalização de termos do IEP I Endereço para correspondência: Amanda Viana dos
Santos. Rua C-254,71 St. Nova Suiça I Email: amandapsico8@gmail.com I doi: 10.18761/PAC.2020.v11.n1.06

Resumo: O método científico proposto pelo Behaviorismo Radical a partir do pragmatismo e do funcionalismo prioriza termos que possibilitam uma definição e análise operacional focada nas variáveis antecedentes e consequentes do comportamento. Essas análises podem contribuir para a área de estudos de Estilos Parentais. O objetivo do estudo foi realizar análises funcionais e definições operacionais das questões presentes no Inventário de Estilos Parentais. O estudo foi realizado nas seguintes etapas: identificar e operacionalizar termos de cada questão em descrições observáveis, identificar relações funcionais entre o ambiente e o comportamento, e formular predições com base nas descrições das relações funcionais. As análises das questões possibilitaram especificar topografias e contextos de ocorrência de diferentes comportamentos parentais e filiais e a posterior identificação de possíveis variáveis de controle presentes em interações baseadas em estilos positivos e em estilos negativos. As possíveis contribuições dessa análise consistem do auxílio na identificação das variáveis envolvidas nas relações funcionais na área de Estilos Parentais. Sugere-se que ela deve ser complementada por observação direta em intervenções voltadas para casos específicos para uma análise funcional mais completa e fidedigna e identificação de outros comportamentos.

Palavras-chave: estilos parentais; IEP; análise funcional; análise conceitual 
Abstract: The scientific method prioritizes terms that enable a definition and operational analysis focused on antecedent and consequent variables. These analyses may contribute for the studies in Parental Styles area. This study is an attempt to perform functional analyses and operational definitions of the items present in the Parenting Styles Inventory. The study was conducted through the following steps: identifying and operationalizing in each items terms in observable descriptions, identifying functional relationships between environment and behavior, and formulating predictions based on the functional relationship descriptions. The analysis of the items made it possible to specify topographies and occurrence contexts of different parental and children behaviors and the subsequent identification of possible control variables present in interactions based on positive and negative styles. The possible contributions of this analysis consist in helping to identify the variables involved in functional relationships about Parental Styles among behavioral scientists. It's suggested direct observation in intervention settings to complement the data for a complete and reliable functional analysis.

Keywords: Parental Styles; IEP; functional analysis, conceptual analysis.

Resumen: El método científico prioriza los términos que permiten la definición y el análisis operacional centrado en las variables antecedentes y consecuentes de comportamiento. Estos análisis pueden contribuir al área de estudios de Estilos Parentales. El objetivo de esto estudio fue realizar análisis funcionales y definiciones operacionales de los ítems presentes en lo Inventario de Estilos Parentales de Gomide. El estudio se realizó en los siguientes pasos: identificación y operacionalización de las preguntas em términos observables, identificación de relaciones funcionales entre el ambiente y la conducta, y formulación de predicciones basadas en descripciones de relaciones funcionales. El análisis de los ítems permitió especificar topografías y contextos de ocurrencia de diferentes comportamientos parentales y de hijos, mas alla posterior identificación de posibles variables de control presentes en interacciones basadas en estilos positivos y negativos. Las posibles contribuciones de este análisis son ayudar a identificar las variables involucradas en las relaciones funcionales sobre estilo parental entre los científicos de la conducta. Se sugiere la observación directa en contextos terapéuticos para complementar los datos para proporcionar un análisis funcional completo y confiable.

Palabras clave: estilos parentales; IEP; análisis funcional; análisis conceptual 
Parte das contingências que atuam fora do ambiente de laboratório estão carregadas pelo uso de termos e definições pouco operacionais de eventos. Skinner (1945) comenta que um grande erro é trazer para o ambiente científico as definições cotidianas de termos do dicionário sem antes criticá-las, pois em grande parte não são sinalizados eventos específicos e mensuráveis, como se operam, bem como em quais circunstâncias são evocados e mantidos. Bachrach (1975) complementa que, apesar de problemas, a definição operacional é fundamental ao método científico e que para se alcançar uma clareza nas definições é necessário se eliminar termos mutuamente compreendidos, mas vagos.

Ainda de acordo com Skinner (1945), de modo geral, a definição de operacionalismo pode ser feita a partir da discussão sobre as observações de um organismo, a manipulação e o cálculo dos procedimentos envolvidos em realizá-los, os passos lógicos e matemáticos para tal, requerendo uma análise funcional, que consiste da análise dos eventos de uma contingência (Matos, 1999; Nery e Fonseca, 2018). De acordo com as autoras, os passos para a realização da análise funcional são identificar e descrever o comportamento público e privado (ou padrões comportamentais); buscar relação entre as variáveis ambientais e comportamentais (ou história de aquisição); identificar processos comportamentais e os possíveis efeitos envolvidos; formular predições com base nas descrições; e testar as predições. Essa análise pode contribuir para o alcance dos objetivos da ciência: a generalidade, o controle e a predição (Skinner, 2000), assim como no contexto de avaliação e intervenção, por favorecer dados mais fidedignos sobre a interação dos indivíduos com o ambiente e, então, o direcionamento da manipulação apropriada das variáveis que controlam o(s) comportamento(s) alvo(s) em questão. Todavia, não há problemas no uso desses termos e definições nesse ambiente externo ao laboratório ou psicoterápico, desde que o comportamento do indivíduo seja reforçado, em múltiplos modos, pela comunidade verbal inserida (Skinner, 1945).

Um dos principais cuidados em definições cientificamente válidas é a necessidade de que elas se baseiem em eventos observáveis (Bachrach, 1975). Constructos não observáveis (Alves, 2013; Smith, 2007; Starling, 2004), como termos mentalistas ou cognitivistas, impossibilitam a identificação do comportamento envolvido e a previsão e controle das variáveis que o controlam, uma vez que são fenômenos inferidos ou inventados, imprecisos e não passíveis de manipulação direta por parte do pesquisador, indo de encontro com a coerência epistemológica da análise do comportamento. Skinner (e.g., 1945, 1991, 2000, 2006) buscou interromper o uso de constructos inventados tradicionalmente utilizados na psicologia, e também a interpretá-los de modo coerente com a proposta do pragmatismo e o funcionalismo do Behaviorismo Radical, uma vez que termos cognitivos podem se referir ao comportamento ou às contingências que os controlam (Dittrich, 2011; Veloso, Tonet, \& Dittrich, 2018; Strapasson, Carrara \& Júnior, 2007).

A preocupação com uso de constructos também foi objeto da filosofia de Ryle (2009), que defende a utilização de termos mentalistas por teóricos desde que não sejam tratados como causa de um comportamento. Por sua vez, a ausência de conceitos adequadamente operacionalizados adequada pode levar aos erros de categoria apontados pelo mesmo autor, como crítica ao dualismo cartesiano. A área de estudos dos estilos parentais podem ser um exemplo desse erro de categoria, por apresentar pouca consistência no uso de termos nas literaturas da área. Essa falta de consistência é compatível com questões levantadas por Bachrach (1975)

\begin{abstract}
Uma frase deste problema de definição pode ser resumida numa citação de Quine que observou que: "quanto menos avançada é uma ciência, tanto mais sua terminologia tende a repousar em uma suposição acrítica de compreensão mútua". Quando indivíduos comunicam observações com termos mutuamente compreendidos mas vagos (tais como personalidade), ao invés de usar termos baseados em fundamentos científicos, a pesquisa é retardada (p. 54).
\end{abstract}

O desenvolvimento do Inventário de Estilos Parentais de Gomide (2006) teve um papel relevante no preenchimento de lacunas referentes à inexistência de instrumentos que avaliassem as necessidades específicas de orientações para as práticas educativas (Sampaio, \& Gomide, 2007). Em virtude disso, as autoras justificam o desenvolvimento do 
instrumento, que desde então tem contribuído para o processo de avaliação e intervenção voltadas para o tratamento infantil e para o treino parental.

O modelo teórico proposto por Gomide (2006) é formado por sete práticas educativas que constituem o Estilo Parental. Para a autora, estilo parental são práticas educativas usufruídas pelos pais na interação com seu filho. Gomide propõe sete práticas: monitoria positiva e comportamento moral (compondo as Práticas Educativas Positivas, oportunas para o desenvolvimento de comportamentos pró-sociais na criança); negligência; punição inconsistente; monitoria negativa; disciplina relaxada; e, abuso físico (que consistem de Práticas Educativas Negativas, favoráveis ao desenvolvimento de comportamentos anti-sociais). A partir dessa sistematização foi desenvolvido o Inventário de Estilos Parentais (IEP, Gomide, 2006), um instrumento composto por 42 frases, que avalia o estilo parental. As frases dessas questões são referentes às possibilidades dos responsáveis de crianças e as crianças se comportarem diante da situação descrita de determinada forma em um conjunto de 10 ocasiões ( 0 a 2 - nunca; 3 a 7 - às vezes; 8 a 10 - sempre). A construção das questões do instrumento se apoiou pelo modelo teórico da autora e vem sendo objeto de estudo por diferentes pesquisadores no Brasil, mostrando sua aplicabilidade para a avaliação dos padrões parentais (Gomide, 2006; Sampaio \& Gomide, 2007).

No IEP, cada conjunto de seis questões relaciona-se a uma das seis práticas e para cada uma das práticas parentais é feita uma pontuação, conforme as frequências - 0 pontos para nunca, 1 ponto para às vezes e 2 pontos para sempre. Ao final, são somadas as práticas positivas e as práticas negativas separadamente. Posteriormente é feita a subtração das práticas positivas pelas negativas, obtendo-se a pontuação referente ao estilo parental.

A partir das frases do inventário, os termos grifados possibilitam um determinado grau de consenso entre falantes e ouvintes, pois permite o intercâmbio entre o profissional e os pais em situação de avaliação e intervenção. Contudo, ao se considerar as operações envolvidas e a identificação de possíveis variáveis de controle dos comportamentos descritos é importante que sejam identificadas essas variáveis, conforme os pressupostos do
Behaviorismo Radical, especialmente no que tange às análises e definições operacionais.

De acordo com Dittrich (2011), uma análise conceitual pode auxiliar a compreensão e intervenção experimental ou aplicada dos fenômenos comportamentais, além de um diálogo producente entre analistas do comportamento sobre os fenômenos comportamentais e suas variáveis de controle envolvidos. Essa proposta contribuiria então para o refinamento de pesquisas na área de estilos parentais e intervenções clínicas analíticas comportamentais infantis.

A análise operacional dos termos psicológicos e a interpretação (funcional) de eventos privados podem gerar consequências relevantes para os analistas do comportamento, como a disseminação da análise do comportamento na área de estudos de estilos parentais, refinamento desta área de estudo conforme o pressuposto pragmático e funcionalista da filosofia Behaviorista Radical (que, por sua vez, implica tecnologias para a análise experimental do comportamento e da análise aplicada do comportamento) e a criação de recursos para o ensino da ciência análise do comportamento (Strapasson, Carrara \& Júnior, 2007; Veloso, Tonet, \& Dittrich, 2018).

Bachrach (1975) ressalta que "uma definição operacional nos diz o que fazer para experimentar uma coisa definida” (p. 55), apesar da linguagem impedir um operacionismo completo. Nesse sentido, uma definição operacional começa com uma observação para uma maior clareza possível, mas que há objeções em virtude do número de definições possíveis. Quanto a isso, Bachrach rebate que "quanto mais nos aproximamos da certeza e da clareza, mais específicos e particulares nos tornamos, enquanto que, em última análise, a própria ciência deve conduzir à generalidade e predição. Não creio que esta objeção ao uso da definição operacional seja legítima. Penso que o número de definições exigidas depende de circunstâncias específicas (p. 55). Em complemento observa que "As observações devem começar sempre com uma definição específica, clara e restrita. Somente com esta base é possível fazer um movimento no sentido de obter uma correlação de observações específicas que contribuam para um corpo de conhecimento mais amplo" (p. 57). Nesse sentido, identificar um possível comportamento e operações às quais ele se 
relaciona pode ser um exemplo de uma possível definição operacional. Em adição, a identificação desses eventos pode possibilitar que sejam inferidas variáveis de controle em uma análise funcional.

O IEP é um instrumento validado que possibilita a avaliação de sujeitos de risco (Sampaio \& Gomide, 2007) e tem sido utilizado em pesquisas e no processo de avaliação em intervenções socialmente relevantes, por apresentar uma sistematização de ações que possibilitam identificar uma dispersão comportamental dos pais frente a diferentes situações (e.g., Gomide, A. Del Prette, \& Z Del Prette, 2003; Gomide, Salvo, Pinheiro, \& Sabbag, 2005; Prust, \& Gomide, 2007; Sabbag, \& BolsoniSilva, 2011, 2015). Visando tentar apresentar uma possível definição operacional, conforme Bachrach (1975) e identificar elementos das contingências presentes nas questões existentes no IEP, a partir de uma perspectiva analítico-comportamental, conforme Mattos (1999), o objetivo do presente trabalho visou desenvolver uma análise operacional e funcional das questões que compõem as práticas positivas e negativas do Inventário de Estilos Parentais (IEP, Gomide, 2006).

\section{Método}

O presente trabalho trata de uma Análise Conceitual dos conceitos presentes nas 42 questões das sete práticas educativas parentais do Inventário de Estilos Parentais (Gomide, 2006), sinalizados na descrição das análises, a partir de análises funcionais e definições operacionais.

\section{Procedimento}

Seguindo os passos descritos por Matos (1999) e por Nery e Fonseca (2018) para a realização de análise funcional e operacional, a Análise Conceitual de termos que compõem as práticas educativas positivas e negativas do modelo proposto de Estilos Parentais do Manual de Inventário de Estilos Parentais foi realizada em etapas:

(1) Sugerir frases específicas para as 42 questões do IEP, a partir da leitura do instrumento pelos autores deste trabalho e discussão sobre os termos que poderiam ser beneficiados de uma ope- racionalização e dos termos propostos para a frase reformulada.

Esse passo foi realizado da seguinte forma: um ou mais conceitos em cada uma das questões do IEP foi destacado e foi realizada uma redação na qual o conceito foi substituído pela respectiva definição operacional proposta, visando manter o contexto da questão. Sua aplicação visou obedecer ao terceiro item da proposta de modificação de operacionalização de Feigl (1945, cit. por Bachrach, 1975, p. 61), segundo a qual as definições "Devem estar empiricamente baseados e ligados ao observável”. Assim, a discussão da reformulação visou identificar se os termos alterados traduziam o conceito original em eventos observáveis e se não incluía inferências que não poderiam ser derivadas a partir da questão original;

(2) identificar relações funcionais entre o ambiente e o comportamento, como a consequência e os antecedentes das questões das sete práticas educativas.

A realização desse passo consistiu em inferir possíveis estímulos antecedentes e consequências que poderiam indicar as variáveis mantenedoras dos comportamentos dos pais em cada uma das questões. Os passos e o critério da análise seguiram as propostas de Matos (1999) e Nery e Fonseca (2018). Evitou-se inferir eventos antecedentes e/ou consequentes que, mesmo possivelmente relacionados à descrição no item, não estão diretamente previstos na questão.; e,

(3) formular predições do comportamento dos responsáveis de criança e do comportamento da criança com base nas descrições das relações funcionais.

Para tal, buscou-se inferir efeitos comportamentais relacionados à frequência do comportamento dos pais ou dos filhos proposto na definição operacional.

Em síntese, a análise dos dados separou cada questão do IEP a partir da leitura do instrumento e identificou termos que pudessem ser reinterpretados a partir de ocorrências ambientais ou comportamentais. Posteriormente foi apresentada uma proposta de análise que traduzisse os termos em ocorrências observáveis na análise operacional e escritos de forma a indicar consequências e/ou contexto em uma análise funcional do item. 


\section{Resultados}

As Tabelas de 1 a 7 apresentam os itens conforme estão no inventário, como proposta de operacionalização visando identificar eventos observáveis envolvidos em cada item, e, proposta a análise funcional em que foram identificadas possíveis variáveis de controle dos comportamentos descritos em cada item.

A seguir são apresentados os resultados para os itens referentes a "Monitoria Positiva", como mostrado na Tabela 1. Foram identificados nas questões termos referentes a sentimentos (por exemplo: triste, aborrecido) e a eventos disposicionais (por exemplo: interesso, "quero saber", ocupado, razões). Na proposta de operacionalização, foram sugeridas topografias (chorando, cabisbaixo, calado, solicito, conte, realizando atividades).

Foi possível operacionalizar e identificar os antecedentes, comportamentos e consequentes de todos os seis itens da prática educativa mencionada. Foram identificadas prioritariamente respostas sob controle de reforçamento positivo, tanto sociais quanto naturais e respostas colaterais decorrentes de reforço positivo.

Na Tabela 2 são apresentados os resultados para os itens referentes ao "Comportamento Moral". Nas seis questões relacionadas a essa prática foram identificados termos que se beneficiariam de uma operacionalização. Os termos relacionaram-se a comportamentos verbais (ensino, aconselho, converso) e a disposições relacionadas a possíveis consequências (melhor, certo, errado). A operacionalização, assim, incluiu termos relacionados a práticas do ensino (indico as consequências, forneço regras, relato e escuto) e a características das consequências.

Com relação à análise funcional, foi possível identificar os antecedentes, comportamentos e consequentes de dois itens e parcialmente quatro itens da prática "Comportamento Moral". Em todos, a presença ou o comportamento do filho foram identificados como antecedente. Nas questões em que foi possível identificar as consequências, foram identificados controles por consequências reforçadoras duradouras de maior magnitude e consequências aversivas de comportamentos inadequados.

A seguir, na Tabela 3 são apresentados os resultados para os itens referentes a "Punição Inconsistente". Os termos amplos identificados nas questões foram "castigar, fazer algo errado, severidade, humor / mal-humor, importar, castigar, nervoso / raiva e descontar. Na operacionalização, fazer algo errado foi definido como emissão de comportamentos inadequados. Castigar, mal-humor, nervoso e raiva descontar foram definidos como tanto a possibilidade de retirada ou agressão, relacionada ao estado emocional ou expressões derivados de experiências negativas e relacionada à intensidade (severidade) da ação paterna.

$\mathrm{Na}$ análise funcional, foram parcialmente operacionalizados e identificados os antecedentes, comportamentos e consequentes dos seis itens da prática "Punição Inconsistente". Em toda as seis questões, pode-se supor que estímulos com efeitos na alteração de respostas emocionais dos pais funcionaram como operação estabelecedora ou abolidora para agir em relação aos filhos, cuja presença ou comportamento funcionaram como estímulos discriminativos para os comportamentos dos pais. As ações dos pais indicam fraca relação de dependência entre os comportamentos dos filhos e os comportamentos dos pais.

$\mathrm{Na}$ Tabela 4 são apresentados os resultados para as questões referentes a "Negligência". Os baixos níveis de interação presentes nas seis questões dessa prática apresentam como termos cuja operacionalização pode apontar para eventos observáveis, como atrapalhar, dificuldades, ocupado, sozinho, sentir, atenção, gostar, ignorar nos contextos específicos das questões referentes à negligência. Por exemplo, atrapalhar pode envolver tanto excesso de trabalho quanto os efeitos físicos (cansaço) relacionados ao trabalho. Ficar sozinho ou não receber atenção indicam eventos nos quais as atividades em casa ou fora dela reduzem o nível de atenção e tem é identificada a partir de comportamentos específicos dos filhos. A dificuldade de dizer o que o filho gosta ou ignorar seus problemas, nos presentes casos sugere que o pai não consegue descrever atividades que são desempenhadas pelos filhos ou suas situações problema.

Verifica-se que foi possível parcialmente identificar os antecedentes, comportamentos e consequentes dos seis itens da prática mencionada. Essas questões indicam uma alta frequência de comportamentos dos pais em alternativas à parentalidade sob controle de outros reforçadores, que limitam o repertório paterno e as interações com os filhos. 


\section{Tabela 1. Descrições da prática "monitoria positiva" no Inventário de Estilos Parentais (IEP), bem como} operacionalizações e análises funcionais.

\begin{tabular}{ll}
\hline Questões - Monitoria Positiva & Operacionalização \\
$\begin{array}{ll}\text { Quando meu filho(a) sai, ele(a) } \\
\text { conta espontaneamente onde vai }\end{array}$ & $\begin{array}{l}\text { Quando meu filho(a) sai, sem } \\
\text { eu perguntar, ele relata onde vai }\end{array}$ \\
$\begin{array}{ll}\text { Pergunto como foi seu dia na } \\
\text { escola e ouço atentamente }\end{array}$ & $\begin{array}{l}\text { Pergunto como foi o dia da } \\
\text { criança na escola e, ao ouvi-la, } \\
\text { aproximo-me em sua direção, }\end{array}$ \\
& $\underline{\text { se puder, olho em seus olhos }}$ \\
& $\underline{\text { e, se tiver oportunidade, realizo }}$ \\
& $\underline{\text { comentários sobre o que é }}$ \\
& $\underline{\text { dito, por exemplo, elogio suas }}$ \\
& $\underline{\text { conquistas. }}$
\end{tabular}

Quando meu filho(a) está triste ou aborrecido(a), interesso-me em ajudá-lo a resolver o problema

Mesmo quando estou ocupado(a) ou viajando, telefono para saber como meu filho(a) está.

Após uma festa, quero saber se meu filho(a) se divertiu

Estabeleço regras (o que pode e o que não pode ser feito) e explico as razões sem brigar.

Quando meu filho está chorando cabisbaixo, calado, isolando-se, que indicam que está em uma situação problema que não consegue resolver, solicito para que me conte sobre o problema e, se eu puder, forneço dicas para ele(a) resolver com a situação.

Mesmo quando estou realizando atividades ou viajando, telefono aproximadamente uma vez ao dia para saber como meu filho está.

Após uma festa, pergunto se meu filho(a) se divertiu

Estabeleço regras (o que pode e o que não pode ser feito) e indico as consequências positivas

\section{Análise Funcional}

No contexto de sair de casa, a presença do seu responsável é um estímulo discriminativo para o filho(a) emitir o relato acerca do local para qual está indo.

A presença da criança após a escola é um estímulo discriminativo para o seu responsável emitir a pergunta acerca do seu dia na escola e, como consequência, produzir o relato da criança. Por sua vez, esse relato funciona como estímulo discriminativo verbal para o responsável emitir respostas de aproximar-se em direção ao filho(a) e, se houver condições para tal, olhar em seus olhos e emitir relatos que reforçam positivamente o comportamento de relatar o dia na escola do filho(a).

$\mathrm{Na}$ situação em que o comportamento do filho(a) está em extinção por não produzir reforçadores positivos e retirada de reforçadores negativos ou porque produziu estimulação aversiva, o responsável emite respostas verbais que evocam a(s) função(ões) do seu comportamento e, se houver repertório para tal, descreve aspectos da contingência que geram os respondentes e sinaliza respostas alternativas e suas respectivas consequências.

Na situação em que grande parte dos comportamentos do responsável está alocada para atividades concorrentes com a parentalidade, este aloca seus comportamentos reforçados pelo contato com o filho com a função de avaliar seu estado corporal.

Na situação em que o filho(a) volta de uma festa, o responsável emite um estímulo discriminativo verbal sobre o evento, com a função de evocar descrições de contingências de reforço positivo que operaram no local. se cumpri-las.
O responsável descreve as contingências para o filho(a): sinaliza os reforçadores positivos que os comportamentos adequados dele(a) poderão entrar em contato ao se comportar de uma dada maneira em um dado estímulo antecedente e as consequências negativas de respostas inadequadas, priorizando as consequências naturais de seus comportamentos 
Tabela 2. Descrições da prática "comportamento moral" no Inventário de Estilos Parentais (IEP), bem como operacionalizações e análises funcionais.

\begin{tabular}{|c|c|c|}
\hline $\begin{array}{l}\text { Questões - Comportamento } \\
\text { Moral }\end{array}$ & Operacionalização & Análise Funcional \\
\hline $\begin{array}{l}\text { Ensino meu filho(a) a devol- } \\
\text { ver objetos ou dinheiro que } \\
\text { não pertencem a ele(a). }\end{array}$ & $\begin{array}{l}\text { Indico ao meu filho(a) consequên- } \\
\text { cias positivas de devolver objetos } \\
\text { ou dinheiro que não lhe perten- } \\
\text { cem. }\end{array}$ & $\begin{array}{l}\text { A presença do(a) filho(a) é um estímulo discriminativo para } \\
\text { o responsável descrever as contingências de reforça- } \\
\text { mento positivo naturais de a criança devolver objetos ou } \\
\text { dinheiro que não lhe pertencem. }\end{array}$ \\
\hline $\begin{array}{l}\text { Se meu filho(a) colar na pro- } \\
\text { va, explico que é melhor tirar } \\
\text { nota baixa do que enganar a } \\
\text { professora ou a si mesmo(a) }\end{array}$ & $\begin{array}{l}\text { Quando meu filho(a) cola na } \\
\text { prova, indico que há mais e maio- } \\
\text { res consequências positivas de } \\
\text { tirar nota baixa que enganar a(o) } \\
\text { professor(a) ou a si mesmo(a). }\end{array}$ & $\begin{array}{l}\text { No contexto de cola na prova, o(a) filho(a) adquire função } \\
\text { de estímulo discriminativo para o responsável descrever } \\
\text { a contingência de reforçamento positivo que tirar nota } \\
\text { baixa produz reforçadores sociais de maior magnitude que } \\
\text { enganar a(o) professor(a) ou a si mesmo(a). }\end{array}$ \\
\hline $\begin{array}{l}\text { Se meu filho(a) estragar algu- } \\
\text { ma coisa de alguém, ensino } \\
\text { a contar o que fez e pedir } \\
\text { desculpas }\end{array}$ & $\begin{array}{l}\text { Quando meu filho(a) estraga } \\
\text { alguma coisa de alguém, indico as } \\
\text { consequências positivas de contar } \\
\text { o que fez e de pedir desculpas } \\
\text { para essa pessoa. }\end{array}$ & $\begin{array}{l}\text { Na situação em que o(a) filho(a) danifica alguma coisa de } \\
\text { alguém, o responsável descreve para ela as contingências } \\
\text { de reforçamento positivas sociais de relatar o compor- } \\
\text { tamento inadequado e ao pedir desculpas para essa } \\
\text { pessoa. }\end{array}$ \\
\hline $\begin{array}{l}\text { Aconselho meu filho(a) a ler } \\
\text { livros, revistas ou ver progra- } \\
\text { mas de TV que mostrem os } \\
\text { efeitos negativos do uso de } \\
\text { drogas. }\end{array}$ & $\begin{array}{l}\text { Forneço regras para meu filho(a) } \\
\text { ler livros, revistas ou ver pro- } \\
\text { gramas de TV que indiquem as } \\
\text { consequências negativas do uso } \\
\text { de drogas. }\end{array}$ & $\begin{array}{l}\text { O responsável apresenta ao(à) filho(a) livros, revistas ou } \\
\text { programas de TV que descrevem as contingências aversi- } \\
\text { vas do consumo de drogas. }\end{array}$ \\
\hline $\begin{array}{l}\text { Converso com meu filho(a) } \\
\text { sobre o que é certo ou } \\
\text { errado no comportamento } \\
\text { dos personagens dos filmes } \\
\text { e dos programas de TV }\end{array}$ & $\begin{array}{l}\text { Relato para meu filho(a) sobre } \\
\text { as consequências positivas e } \\
\text { negativas produzidas pelos com- } \\
\text { portamentos dos personagens dos } \\
\text { filmes e dos programas de TV, e } \\
\text { o escuto quando ele(a) fala sobre } \\
\text { essas consequências. }\end{array}$ & $\begin{array}{l}\text { Na presença do(a) filho(a), o responsável descreve as } \\
\text { contingências de reforçamento positivas e aversivas que } \\
\text { operam nos comportamentos personagens dos filmes e } \\
\text { dos programas de TV, e reforça positivamente por meio da } \\
\text { atenção o comportamento do(a) filho(a) de relatar sobre } \\
\text { essas consequências. }\end{array}$ \\
\hline $\begin{array}{l}\text { Converso sobre o futuro } \\
\text { trabalho ou profissão de meu } \\
\text { filho, mostrando os pontos } \\
\text { positivos ou negativos de sua } \\
\text { escolha }\end{array}$ & $\begin{array}{l}\text { Relato para meu filho(a) sobre } \\
\text { seu futuro trabalho ou profissão, } \\
\text { apresentando as consequências } \\
\text { positivas e negativas de sua esco- } \\
\text { Iha, e o escuto quando fala sobre } \\
\text { essas consequências. }\end{array}$ & $\begin{array}{l}\text { Na presença do(a) filho(a), o responsável descreve as } \\
\text { contingências de reforçamento positivas e aversivas da } \\
\text { escolha do futuro trabalho ou profissão da criança, e } \\
\text { reforça positivamente por meio da atenção o seu compor- } \\
\text { tamento de relatar sobre essas consequências. }\end{array}$ \\
\hline
\end{tabular}

A Tabela 5 apresenta os resultados dos itens referentes à "Disciplina Relaxada". Além de termos já definidos em outras questões, como castigar, nervoso e percebe, para os termos ameaçar, insistir, gritar, e desobedecer foram propostas operacionalizações que apontam para topografias de verbalização hostil, alta frequência de solicitações, aumento do tom de voz. Ao mesmo tempo, compatível com a prática de disciplina relaxada, aparecem os termos deixar em paz, "deixar para lá", hora "H" e pena que indicam que nos respectivos contextos cessam discussão, não fazem o que disseram.
Foi possível operacionalizar e identificar os antecedentes, comportamentos e consequentes dos seis itens da prática mencionada. Os comportamentos inadequados dos filhos são controlados nas diferentes questões por regras que apontam para contingências aversivas ou envolvem interações aversivas com os pais, que fornecem regras que estão em desacordo com as contingências que operam posteriormente. 


\section{Tabela 3. Descrições da prática "punição inconsistente" no Inventário de Estilos Parentais (IEP), bem como} operacionalizações e análises funcionais.

Questões - Punição incon- Operacionalização
sistente

Quando meu filho(a) faz algo errado, a punição que aplico é mais severa dependendo do meu humor.

Quando estou alegre, não me importo com as coisas erradas que meu filho(a) faça.

Castigo-o quando estou nervoso(a); assim que passa a raiva, peço desculpas.

Quando estou nervoso(a), acabo descontando em meu filho(a).

Sou mal-humorado(a) com meu filho.

Quando estou mal-humorado(a), não deixo meu filho(a) sair com os amigos.
Quando meu filho(a) se comporta da punição que aplico pode ser maior dependendo do meu estado emocional decorrente de minhas experiências positivas ou negativas não relacionadas à parentalidade.

Deixo de intervir nos comportamentos inadequados do meu filho(a) se meu estado emocional for alegre, decorrente de minhas experiências positivas.

Retiro do meu filho(a) a possibilidade de se engajar em alguma atividade por um determinado tempo e/ou uso de agredir física ou verbalmente contra seu corpo, se eu apresentar um estado emocional de raiva decorrente de minhas experiências negativas. Quando me acalmo, vou até ele(a) e lhe peço desculpas

Se apresento um estado emocional nervoso decorrente de minhas experiências negativas, acabo agredindo meu (minha) filho(a) fisica ou verbalmente e/ou retirando-lhe privilégios.

Em relação ao meu filho(a), fico com expressão facial de raiva, confronto aos seus desejos ou opiniões, respondo grosseiramente e com uma única entonação de voz, cito mais seus comportamentos negativos do que positivos, entre outros.

Não deixo meu filho(a) sair com os amigos se apresento um estado emocional negativo decorrente de minhas experiências negativas.
Análise Funcional

No contexto do(a) filho(a) se comportar inadequadamente, o efeito emocional das contingências de reforçamento positivas ou aversivas que operam sobre o comportamento do responsável, concorrentes com a parentalidade, é condição antecedente estabelecedora para a variação na intensidade da punição do comportamento do(a) filho(a).

$\mathrm{Na}$ condição antecedente estabelecedora do efeito emocional das contingências de reforçamento positivas que operam sobre o comportamento do responsável, este não aplica consequências contingentes aos comportamentos inadequados do(a) filho(a).

No contexto do(a) filho(a) estar presente, a resposta emocional das contingências aversivas que operam sobre o comportamento do responsável é condição antecedente estabelecedora para retirar ou restringir atividades que produzem reforçadores positivos para o comportamento do filho(a) e/ou usar força física contra seu corpo. No contexto com função abolidora para a resposta emocional diminuir, o(a) filho(a) adquire função discriminativa para o responsável pedir-lhe desculpas.

No contexto da presença do filho(a), o efeito emocional das contingências aversivas que operam sobre o comportamento do responsável é condição antecedente estabelecedora para, em relação a seu filho(a), usar a força física contra seu corpo e/ou retirar-lhe atividades que produzem reforçadores positivos e/ou falar em um tom mais alto que em outros contextos.

A presença do(a) filho(a) adquire função de estímulo discriminativo que evoca comportamentos do responsável de confrontar aos desejos ou opiniões do filho(a), responder com o mínimo de palavras possíveis e com uma entonação de voz indicativa de seu estado emocional alterado.

No contexto do(a) filho(a) indicar que sairá com os amigos, o efeito emocional das contingências aversivas que operam sobre o comportamento do responsável, concorrentes com a parentalidade, é condição antecedente estabelecedora para não reforçar o comportamento do(a) filho(a). 
Tabela 4. Descrições da prática "negligência" no Inventário de Estilos Parentais (IEP), bem como operacionalizações e análises funcionais.

\begin{tabular}{|c|c|c|}
\hline Questões - Negligência & Operacionalização & Análise Funcional \\
\hline $\begin{array}{l}\text { Meu trabalho atrapalha na } \\
\text { atenção que dou a meu } \\
\text { filho(a). }\end{array}$ & $\begin{array}{l}\text { Passo mais tempo trabalhando do que } \\
\text { com meu filho(a), e/ou por o trabalho me } \\
\text { cansar, prefiro me engajar em outras ativi- } \\
\text { dades alternativas à parentalidade. }\end{array}$ & $\begin{array}{l}\text { O responsável aloca a maior parte de seus com- } \\
\text { portamentos para o trabalho, e/ou por em virtude } \\
\text { desta atividade aloca seus comportamentos para } \\
\text { atividades concorrentes à parentalidade. }\end{array}$ \\
\hline $\begin{array}{l}\text { Meu filho(a) sente dificulda- } \\
\text { des em contar seus pro- } \\
\text { blemas para mim, pois vivo } \\
\text { ocupado(a). }\end{array}$ & $\begin{array}{l}\text { O meu longo tempo engajado em outras } \\
\text { atividades não relacionadas a parentali- } \\
\text { dade limita as oportunidades do meu filho } \\
\text { contar seus problemas para mim. }\end{array}$ & $\begin{array}{l}\text { No contexto do responsável alocar a maior parte } \\
\text { de seus comportamentos para atividades concor- } \\
\text { rentes com a parentalidade, este adquire função } \\
\text { de estímulo delta para o(a) filho(a) descrever } \\
\text { contingências aversivas que operam sobre seus } \\
\text { comportamentos. }\end{array}$ \\
\hline $\begin{array}{l}\text { Meu filho(a) fica sozinho em } \\
\text { casa a maior parte do tempo. }\end{array}$ & $\begin{array}{l}\text { Meu filho(a) fica mais tempo em casa sem } \\
\text { algum responsável. }\end{array}$ & $\begin{array}{l}\text { No contexto do(a) filho estar em sua casa, o(s) } \\
\text { responsável(is) aloca }(\mathrm{m}) \text { a maior parte dos seus } \\
\text { comportamentos a atividades externas ou não à } \\
\text { casa, concorrentes com a parentalidade e, como } \\
\text { efeito, a criança passa mais tempo sozinha do que } \\
\text { interagindo com algum responsável. }\end{array}$ \\
\hline $\begin{array}{l}\text { Percebo que meu filho(a) } \\
\text { sente que não dou atenção } \\
\text { a ele(a). }\end{array}$ & $\begin{array}{l}\text { Tenho me dedicado mais a atividades } \\
\text { não relacionadas com a parentalidade, e } \\
\text { como efeito, observo, na minha presença, } \\
\text { comportamentos no meu filho(a) como ca- } \\
\text { bisbaixo, pedindo atenção, entre outros. }\end{array}$ & $\begin{array}{l}\text { No contexto do responsável alocar a maior parte } \\
\text { de seus comportamentos para atividades concor- } \\
\text { rentes com a parentalidade, a sua presença é o } \\
\text { estímulo discriminativo para o(a) filho(a) emitir com- } \\
\text { portamentos que indicam a privação de estímulos } \\
\text { reforçadores sociais, como os comportamentos de } \\
\text { ficar cabisbaixo e/ou o mando por atenção. }\end{array}$ \\
\hline $\begin{array}{l}\text { Não sei dizer do que meu } \\
\text { filho(a) gosta. }\end{array}$ & $\begin{array}{l}\text { Não identifico as atividades que meu } \\
\text { filho(a) passa a maior parte do tempo se } \\
\text { engajando. }\end{array}$ & $\begin{array}{l}\text { O responsável não possui repertório para descre- } \\
\text { ver as contingências de reforçamento positivo que } \\
\text { operam nos comportamentos do(a) filho(a). }\end{array}$ \\
\hline $\begin{array}{l}\text { Ignoro os problemas de meu } \\
\text { filho(a). }\end{array}$ & $\frac{\text { Tenho baixa probabilidade de descrever }}{\text { as situações problema de meu filho(a). }}$ & $\begin{array}{l}\text { A situação problema em que o(a) filho(a) se encon- } \\
\text { tra é um estímulo delta para o responsável emitir } \\
\text { algum comportamento em relação à essa situação. }\end{array}$ \\
\hline
\end{tabular}

Os dados da Tabela 6 referentes à prática "Monitoria Negativa" apresentam termos que podem se beneficiar de operacionalização ao indicar relações voltadas para comportamentos dos pais, como: "Critico", ao apontar para indicação de aspectos negativos do comportamento; "Controlo", ao sugerir busca ativa de informações e "Insistindo", com pedidos repetidos; além de relações voltadas para comportamentos dos filhos: "quarto desarrumado", indicando bagunçar o quarto; "aborrecido", que pode envolver as respostas observáveis de chorar, ficar cabisbaixo, ficar calado ou isolar-se.

Foram operacionalizados e identificados os antecedentes, comportamentos e consequentes dois itens e parcialmente quatro itens da prática "Monitoria Negativa". Em consonância com os cri- térios da prática, há controle do comportamento por verbalizações que direcionam-se a consequências aversivas, com alta frequência de emissão de respostas parentais coercitivas a uma gama de comportamentos dos filhos.

Os dados apresentados na Tabela 7 são referentes à prática "Abuso Físico" envolvem termos que apontam para ações de sanções físicas (bater, agressão, violência) e efeitos de comportamentos agressivos dos pais relacionados dessas ações sobre os comportamento dos filhos (medo, machucado, ódio). As operacionalizações das ações apontam para o contato físico (utilizar contra o corpo ou agredir verbal / fisicamente) e respostas (tremer, esconder, pedir para não bater), marcas físicas na pele, ou respostas verbais e não verbais (verbalizar sentimentos negativos, parar de conversar). 


\section{Tabela 5. Descrições da prática "disciplina relaxada" no Inventário de Estilos Parentais (IEP), bem como} operacionalizações e análises funcionais.

\begin{tabular}{ll}
\hline $\begin{array}{l}\text { Questões - Disciplina } \\
\text { Relaxada }\end{array}$ & Operacionalização \\
\hline $\begin{array}{l}\text { Ameaço que vou bater ou } \\
\text { castigar e depois não faço } \\
\text { nada. }\end{array}$ & $\begin{array}{l}\text { Quando meu filho(a) se comporta inade- } \\
\text { quadamente, verbalizo de forma hostil que } \\
\text { vou agredi-lo e/ou retirar alguma de sua } \\
\text { gratificação por um determinado tempo, }\end{array}$ \\
& $\begin{array}{l}\text { mas não faço o que eu digo. } \\
\end{array}$
\end{tabular}

Quando castigo meu filho(a) e ele pede para sair do castigo, após um pouco de insistência, permito que saia do castigo.

\section{Durante uma briga, meu} filho(a) xinga ou grita comigo e, então, eu o(a) deixo em paz.

Quando mando meu filho(a) estudar, arrumar o quarto ou voltar para casa, e ele não obedece, eu "deixo para lá".
Quando meu filho(a) se comporta inadequadamente, retiro alguma(s) de sua(s) atividades por um determinado tempo, mas se ele solicita repetidas vezes para que saia dessa situação, permito que saia do castigo.

Em uma briga com meu filho(a), se ele(a) xinga e/ou aumenta seu tom de voz, me calo e/ou me afasto, parando de discutir.

Quando digo para meu filho(a) estudar, arrumar o quarto ou voltar para casa, $\underline{\mathrm{e}}$ ele não faz o que eu disse, não falo e faço nada em relação à situação.

Apresento a regra para meu filho(a) que se se engajar em atividades alternativas com o estudo, não irá receber um presente, mas, no momento definido para fornecer o presente, mesmo não se engajando, fico pensando sobre sua dor e dando o presente mesmo assim.

Em uma discussão ou briga com meu filho(a), quando ele aumenta o tom de sua voz, xinga, entre outros, infiro que ele percebe que me sinto amedrontado(a).
Análise Funcional

O(a) filho(a) se comportar inadequadamente adquire função discriminativa para o responsável descrever vocalmente uma contingência de punição positiva ao usar a força física contra seu corpo e/ou negativa ao retirar estímulos reforçadores positivos por um determinado tempo, mas não libera as consequências indicadas, não havendo correspondência entre o dizer e o fazer.

No contexto do(a) filho(a) se comportar inadequadamente e o responsável retirar estímulos reforçadores positivos por um determinado tempo, a criança emitir o mando pelo menos mais de uma vez para que saia dessa contingência aversiva que opera sobre seus comportamentos, adquire função para o responsável reforçar o seu mando.

No contexto de uma briga com o filho(a), este emitir comportamentos como xingar e/ou aumentar seu tom de voz, adquire função para o responsável reforçar negativamente o comportamento da criança.

No contexto do filho(a) alocar seus comportamentos para atividades concorrentes com o estudar, arrumar o quarto ou voltar para casa, o responsável emite o mando de se comportar para essas atividades. A criança não reforçar o comportamento do responsável, continuando alocar seus comportamentos para atividades concorrentes está sob uma contingência de extinção. Há ausência de correspondência entre dizer e fazer.

No contexto do responsável descrever para o(a) filho(a) a contingência que se alocar seus comportamentos em atividades concorrentes com o estudar, estes não serão reforçados com um presente, o filho(a) não seguir a regra adquire função de eliciador do sentimento de pena e discriminativa para liberar o reforço positivo (presente) não contingente ao comportamento, não havendo, assim, correspondência entre o dizer e o fazer.

No contexto de discussão ou briga entre o responsável e o(a) filho(a), quando este aumenta o tom de voz, chora e/ou xinga, entre outros, o responsável infere que esses comportamentos estão sob controle da diminuição da frequência e intensidade dos comportamentos aversivos do responsável e estabelecimento de respostas emocionais de medo.
A partir das operações apontadas foi possível identificar os antecedentes, comportamentos e consequentes um item e parcialmente cinco itens da prática "Abuso Físico". Dentre as variáveis identificadas, compativelmente com a descrição da prática, a presença ou o comportamento do filho é estímulo discriminativo para respostas de agressão, que têm como efeito marcas respostas emocionais e emissão de respostas verbais sob controle da evitação das agressões. Dada a ausência de outros efeitos operantes não é possível identificar se as relações envolvem reforço ou punição. 
Tabela 6. Descrições da prática "monitoria negativa" no Inventário de Estilos Parentais (IEP), bem como operacionalizações e análises funcionais.

\begin{tabular}{|c|c|c|}
\hline $\begin{array}{l}\text { Questões - Monitoria } \\
\text { Negativa }\end{array}$ & Operacionalização & Análise Funcional \\
\hline $\begin{array}{l}\text { Critico qualquer coisa que } \\
\text { meu filho(a) faça, como o } \\
\text { quarto estar desarrumado } \\
\text { ou estar com os cabelos } \\
\text { despenteados. }\end{array}$ & $\begin{array}{l}\text { Indico os aspectos negativos da maioria } \\
\text { dos comportamentos do meu filho(a), } \\
\text { como bagunçar o seu quarto ou não pen- } \\
\text { tear os cabelos. }\end{array}$ & $\begin{array}{l}\text { Grande parte dos comportamentos do(a) filho(a), } \\
\text { como bagunçar o quarto ou não pentear os } \\
\text { cabelos, adquirem função discriminativa para o } \\
\text { responsável emitir comportamentos vocais com } \\
\text { função punitiva. }\end{array}$ \\
\hline $\begin{array}{l}\text { Quando meu filho(a) sai, te- } \\
\text { lefono procurando por ele(a) } \\
\text { muitas vezes. }\end{array}$ & $\begin{array}{l}\text { Quando meu filho(a) sai, telefono seguida- } \\
\text { mente para ele ou para alguém que está } \\
\text { junto dele. }\end{array}$ & $\begin{array}{l}\text { No contexto do(a) filho(a) estar fora de casa, o } \\
\text { responsável emite o comportamento de telefonar } \\
\text { com alta frequência para ele(a) ou para alguém } \\
\text { que está junto dele(a). }\end{array}$ \\
\hline $\begin{array}{l}\text { Controlo com quem meu } \\
\text { filho(a) fala ou sai. }\end{array}$ & $\begin{array}{l}\text { Procuro ativamente informações sobre de } \\
\text { quem meu filho(a) é amigo ou conhecido } \\
\text { e digo se pode ou não conversar ou sair. }\end{array}$ & $\begin{array}{l}\text { Após adquirir o repertório de saber quem o filho(a) } \\
\text { é amigo ou conhecido, o responsável emite a regra } \\
\text { que descreve com quem ele(a) pode conversar } \\
\text { ou sair, indicando a correlação de consequências } \\
\text { punitivas pelo não seguimento. }\end{array}$ \\
\hline $\begin{array}{l}\text { Especialmente nas horas } \\
\text { das refeições, fico dando as } \\
\text { "broncas". }\end{array}$ & $\begin{array}{l}\text { Especialmente nos momentos das refei- } \\
\text { ções, puno os comportamentos inadequa- } \\
\text { dos do meu filho(a) daquele momento ou } \\
\text { de outros. }\end{array}$ & $\begin{array}{l}\text { No contexto das refeições, o filho(a) adquire fun- } \\
\text { ção discriminativa para o responsável emitir vocais } \\
\text { com função punitiva sobre os seus comportamen- } \\
\text { tos inadequados emitidos naquele contexto ou em } \\
\text { outros concorrentes. }\end{array}$ \\
\hline $\begin{array}{l}\text { Se meu filho(a) vai a uma } \\
\text { festa, somente quero saber } \\
\text { se bebeu, se fumou ou se } \\
\text { estava com aquele grupo de } \\
\text { maus elementos. }\end{array}$ & $\begin{array}{l}\text { Quando meu filho(a) chega de uma festa, } \\
\text { pergunto se bebeu, se fumou ou se esta- } \\
\text { va junto com o grupo de pessoas que eu } \\
\text { considero inadequado para ele. }\end{array}$ & $\begin{array}{l}\text { No contexto do(a) filho(a) ter chegado de uma } \\
\text { festa, esta adquire função discriminativa para o } \\
\text { responsável emitir perguntas de se bebeu, se } \\
\text { fumou ou se estava junto ao grupo de pessoas que } \\
\text { são modelos e reforçam comportamentos que o } \\
\text { responsável considera inadequados. }\end{array}$ \\
\hline $\begin{array}{l}\text { Se meu filho(a) estiver } \\
\text { aborrecido(a), fico insistindo } \\
\text { para ele contar o que acon- } \\
\text { teceu, mesmo que ele(a) não } \\
\text { queira contar. }\end{array}$ & $\begin{array}{l}\text { Quando meu filho está chorando, cabis- } \\
\text { baixo, calado e/ou isolando-se que indi- } \\
\text { cam que está em uma situação problema, } \\
\text { peço repetidamente para que ele me } \\
\text { conte o que aconteceu. }\end{array}$ & $\begin{array}{l}\text { No contexto do(a) filho(a) estar em uma situação } \\
\text { problema, seus comportamentos de estar choran- } \\
\text { do, cabisbaixo, calado e/ou isolando-se, adquirem } \\
\text { função discriminativa para o responsável emitir o } \\
\text { mando para que descreva a contingência aversiva } \\
\text { que seus comportamentos estão sob controle, } \\
\text { ainda que a criança só reforce seu comportamento } \\
\text { quando ele o emite pelo menos mais de uma vez. }\end{array}$ \\
\hline
\end{tabular}

Em suma, foram realizadas, pelos autores deste artigo, operacionalizações trazidas nas segundas colunas das tabelas em relação às questões originais do IEP apresentadas na primeira coluna, além das análises funcionais a partir da proposta do instrumento análises operacionais e análises funcionais a partir da proposta do IEP. Nessas análises, houve termos que por apareceram em forma de ações, tiveram uma operacionalização mais direta. Já os termos que apareceram de forma disposicional foram operacionalizados a partir de possíveis ocorrências frequentemente associadas a essas disposições, como: quero à pergunto; me interesso à solicito para que me conte; humor à estado emocional decorrente de minhas experiências; percebo à observo; e, não me importo à deixo de intervir.

As descrições e análises dos estados corporais, como raiva ou alegria, foram limitadas no escopo das informações acerca das condições ambientais fornecidas nas questões do IEP. Quanto às análises funcionais, os elementos menos identificados referem-se às possíveis consequências. 


\section{Tabela 7. Descrições da prática "abuso físico" no Inventário de Estilos Parentais (IEP), bem como} operacionalizações e análises funcionais.

\begin{tabular}{|c|c|c|}
\hline Questões -Abuso físico & Operacionalização & Análise Funcional \\
\hline $\begin{array}{l}\text { Bato com cinta ou outros } \\
\text { objetos nele(a). }\end{array}$ & $\begin{array}{l}\text { Utilizo contra o corpo do meu filho(a) cinta } \\
\text { ou outros objetos. }\end{array}$ & $\begin{array}{l}\text { O(a) filho(a) se comportar inadequadamente é o } \\
\text { contexto para responsável usar estimulação aversiva, } \\
\text { como cinta ou outros objetos contra seu corpo. }\end{array}$ \\
\hline $\begin{array}{l}\text { Meu filho(a) tem muito } \\
\text { medo de apanhar de mim. }\end{array}$ & $\begin{array}{l}\text { A minha presença é suficiente para que } \\
\text { ele se esconda, trema, peça para que eu } \\
\text { não bata nele e/ou chore. }\end{array}$ & $\begin{array}{l}\text { No contexto do(a) filho(a) se comportar inadequa- } \\
\text { damente, a presença do responsável é um estímulo } \\
\text { discriminativo para ele(a) emitir comportamentos de } \\
\text { fuga ou esquiva e/ou mandos para que não utilize de } \\
\text { força física contra seu corpo, e/ou elicie responden- } \\
\text { tes como tremer, entre outros. }\end{array}$ \\
\hline $\begin{array}{l}\text { Meu filho(a) fica machuca- } \\
\text { do fisicamente quando bato } \\
\text { nele(a). }\end{array}$ & $\begin{array}{l}\text { Quando meu filho se comporta inadequa- } \\
\text { damente, o agrido fisicamente e, depois, } \\
\text { posso observar resultados como marcas } \\
\text { em sua pele e/ou alguma parte de seu } \\
\underline{\text { corpo. }}\end{array}$ & $\begin{array}{l}\text { No contexto do filho(a) se comportar inadequadamen- } \\
\text { te, a sua presença evoca comportamentos do respon- } \\
\text { sável de agredi-lo, como consequência, é aparentado } \\
\text { marcas na pele e/ou alguma parte do corpo. }\end{array}$ \\
\hline $\begin{array}{l}\text { Meu filho(a) sente ódio de } \\
\text { mim quando bato nele(a). }\end{array}$ & $\begin{array}{l}\text { Quando meu filho(a) se comporta inade- } \\
\text { quadamente e eu utilizo de força física } \\
\text { contra seu corpo, ele verbaliza seus } \\
\text { sentimentos negativos em relação a mim, } \\
\text { para de falar comigo por um determinado } \\
\text { tempo e/ou expressa facialmente raiva, } \\
\text { entre outros. }\end{array}$ & $\begin{array}{l}\text { No contexto do(a) filho(a) se comportar inadequada- } \\
\text { mente e o responsável utilizar força física contra o } \\
\text { seu corpo, o responsável adquire função discrimina- } \\
\text { tiva para a criança indicar vocalmente seus senti- } \\
\text { mentos aversivos, ficar em silêncio ou discutir com } \\
\text { ele e/ou expressar facialmente raiva, entre outros. }\end{array}$ \\
\hline $\begin{array}{l}\text { Sou agressivo(a) com meu } \\
\text { filho(a). }\end{array}$ & $\begin{array}{l}\frac{\text { Interajo com meu filho utilizando verba- }}{\text { lizações como xingamento, sacarmos, }} \\
\text { ironias, aumento o meu tom de voz, entre } \\
\text { outros. }\end{array}$ & $\begin{array}{l}\text { O(a) filho(a) é um estímulo discriminativo para o res- } \\
\text { ponsável emitir comportamentos de xingar, aumentar } \\
\text { seu tom de voz, sacarmos, ironias, entre outros. }\end{array}$ \\
\hline $\begin{array}{l}\text { Sou violento(a) com meu } \\
\text { filho(a). }\end{array}$ & $\begin{array}{l}\text { Utilizo agressão física ou verbal contra } \\
\text { meu filho(a) na maioria das situações. }\end{array}$ & $\begin{array}{l}\text { O responsável emite comportamentos de agressão } \\
\text { física ou verbal contra seu filho com mais frequência } \\
\text { que comportamentos alternativos de afeto ou carinho. }\end{array}$ \\
\hline
\end{tabular}

\section{Discussão}

A partir das propostas de Bachrach (1975) e Skinner (1961), essa análise operacional e funcional pode complementar as definições de eventos e termos relativos às práticas educativas parentais formuladas a partir do método científico proposto pelo Behaviorismo Radical a partir dos pressupostos pragmáticos e funcionalistas. Foram realizadas tentativas de operacionalização dos termos cotidianos presentes nas questões do IEP para descrições dos comportamentos parentais e filiais, evitando cair no "erro de categoria", de acordo com a proposta de Ryle (1949/2009) como crítica ao dualismo cartesiano. A área de estudos dos estilos parentais pode ser um exemplo desse erro de categoria, por apresentar pouca consistência no uso de termos nas literaturas da área. Como efeito, essa análise pode minimizar confusões, tanto de quem usufrui a pesquisa, quanto para o próprio cientista, acerca de qual(is) evento(s) está(ão) sendo observado(s) e/ ou manipulado(s), além do alcance dos objetivos da ciência (generalidade, controle e predição, de acordo com Skinner, 2000) e no contexto psicoterápico a partir de descrição de variáveis específicas que controlam a queixa do cliente.

Para a operacionalização foi aplicado o critério 3 de Fiegl reformulado por Bachrach (1975) e para a análise funcional foram seguidos os passos 1 a 3 de Matos (1999) e de Nery \& Fonseca (2018) dos termos das práticas educativas parentais que compõem as 42 questões do IEP, como forma de sinalizar quais eventos estão sendo tratados, como eles se operam e, em quais circunstâncias são evocados e mantidos. Assim, foram analisadas disposições (ou condições ambientais) do conhecimento (ou comportamento) ocorrer de cada item descrito do inventário, compatível com a proposta de Ryle (1949/2009), utilizando o menor número possível 
de constructos direcionados a eventos não observáveis (Alves, 2013; Smith, 2007; Starling, 2004;), uma vez que termos cognitivos podem se referir ao comportamento ou às contingências que os controlam (Dittrich, 2011; Veloso, Tonet, \& Dittrich, 2018; Strapasson, Carrara \& Júnior, 2007.

Por outro lado, Ryle (1949/2009) defende a utilização de termos mentalistas por teóricos desde que sejam utilizados de maneira lógica, isto é, não serem tratados como causa de um comportamento. Em um sentido próximo, Skinner (1961) menciona que desde que os comportamentos de um organismo obtenham seus reforçadores pela comunidade verbal inserida, não há empecilhos no uso de termos cotidianos com definições que carecem de uma operacionalização e/ou de uma análise funcional. Assim, ressalta-se as dificuldades encontradas no momento da análise de identificação de todos os elementos da contingência de cada prática, não sendo sempre possível, visto que a forma de apresentação para o público leigo, público alvo do inventário, torna desnecessária a especificação desses termos, visto as descrições das práticas já fazerem parte das respectivas comunidades verbais, referendadas pelos procedimentos de validação aos quais o inventário foi submetido (Gomide, 2006). Porém, ao se depararem com os itens, pais respondem a aspectos ontogenéticos e as variáveis de controle sob as quais foram submetidos, e a inferência desses elementos ou de possíveis relações não diretamente apontadas não é indicada em uma análise funcional.

Uma análise conceitual pode auxiliar a compreensão e intervenção experimental ou aplicada dos fenômenos comportamentais, além de um diálogo producente entre analistas do comportamento sobre os fenômenos comportamentais e suas variáveis de controle envolvidos, contribuindo para o refinamento de pesquisas na área de estilos parentais e intervenções clínicas analíticas comportamentais infantis (Dittrich, 2011). A presente análise consistiu de sugestões de definições de termos originais a serem utilizados na prática clínica no contexto da análise das práticas educativas parentais, possibilitando para o psicólogo clareza das relações entre os eventos tratados.

Ressalta-se que o IEP é um inventário validado e com grande consistência interna, o que tem possibilitado sua utilização de forma eficaz no processo de avaliação dos padrões parentais, tanto sob a ótica dos pais quanto sob a ótica dos filhos. Seu grande diferencial é utilizar questões que têm alto nível de compreensão ao serem respondidas. Dessa forma, o presente trabalho não se constitui como uma crítica, ou proposta de adequação do questionário. Além disso, o presente estudo pode favorecer o esclarecimento dos dados junto aos pais após aplicação do IEP, para maior compreensão das variáveis diretamente envolvidas nas interações com os filhos em cada caso concreto, as quais podem ser possíveis de se investigar em complemento à aplicação do instrumento. Isso pode contribuir para maior coleta de informações e para o direcionamento estratégico interventivo adequado para cada situação, além de abrir espaço para a aplicação dos passos 4 e 5 da análise funcional descrita por Matos (1999), com o teste das relações identificadas na própria intervenção. A título de exemplo, ao pai responder que "castigo-o quando estou nervoso", o terapeuta tentará identificar se há maior frequência de retirada de possibilidade de engajar em alguma atividade ou agressão, aplicando o passo 4 da análise funcional. Adicionalmente, testaria intervenções específicas para lidar com os padrões identificados, aplicando o passo 5 .

As descrições e análises dos estados corporais foram limitadas visto que, "em geral, a variedade e nuanças das emoções sugerem que tentar classificá-las definitivamente seria quase impossível" (Kohlenberg \& Tsai, 2006, p. 77).

A Análise Experimental do Comportamento, bem como a Análise Aplicada do Comportamento usufruem da análise funcional para a descrição comportamental de um modo mais completo. Por sua vez, reconhece-se que a análise conceitual, sozinha, não é suficiente para o crescimento da análise do comportamento (Strapasson, Carrara \& Júnior, 2007). Por fim, Skinner (2006) aponta que a análise operacional e funcional de termos cognitivos pode alterar o sentido da palavra original, sendo inviável propor definições desse sentido original. Contudo, com relação à operacionalização, deve-se considerar a posição de Bachrach (1975) de que um mesmo termo pode ter mais de uma definição e, nesse sentido cada definição aqui apresentada é uma proposta e contextos parentais específicos podem levar à identificação de outros eventos observáveis 
que estão controlando os comportamentos dos pais e, consequentemente, o comportamento dos filhos.

Assim, sugere-se, de acordo com a proposta de Skinner (1961), a observação direta para complementação dos dados para uma análise funcional e operacional completa e fidedigna, alinhado a procedimentos de diferentes manipulações.

As análises dos itens possibilitaram especificar topografias e contextos de ocorrência de diferentes comportamentos parentais e filiais e a posterior identificação de possíveis variáveis de controle presentes em interações baseadas em estilos mais positivos ou em estilos mais negativos. Em termos gerais, as práticas positivas ao serem analisadas envolveram prioritariamente reforço positivo voltado para comportamentos benéficos, ao passo que as práticas negativas envolveram baixo nível de reforço positivo e alto nível de coerção. Com isso, os presentes dados podem contribuir para o direcionamento de tratamentos infantis ou de treinamentos parentais.

\section{Referências}

Alves, D. Z. (2013). Análise do comportamento e neurociências: em busca de uma possível síntese (Tese de doutorado, Universidade de São Paulo).

Bachrach, A. J. (1975). Introdução à pesquisa psicológica. Trad. Geraldine Porto Witter. São Paulo: EPU

Dittrich, A. (2011). Possibilidades da investigação conceitual/filosófica na análise do comportamento. Interação em Psicologia, 27-33. DOI: http://dx.doi.org/10.5380/psi.v15i0.25369

Gomide, P. I. C. (2006). Inventário de estilos parentais: modelo teórico, manual de aplicação, apuração e interpretação. Petrópolis: Vozes.

Gomide, P. I. C., Del Prette, A., \& Del Prette, Z. A. P. (2003). Estilos parentais e comportamento anti-social. Habilidades sociais, desenvolvimento e aprendizagem, 1, 21-60.

Gomide, P. I. C., Salvo, C. G. D., Pinheiro, D. P. N., \& Sabbag, G. M. (2005). Correlação entre práticas educativas, depressão, estresse e habilidades sociais. PsicoUSF, 10(2), 169-178.

Kohlenberg, R. J., \& Tsai, M., (2006). Psicoterapia analítica funcional [Functional analytic psychotherapy: Creating intense and curative therapeutic relationships] (R. R. Kerbauy, Trans.). Santo André: Esetec. (Original work published 1991). Matos, M. A. (1999). Análise funcional do comportamento. Estudos de Psicologia, 16(3), 8-18.

Fonseca, F. N. \& Nery, L. B. (2018). Formulação comportamental ou diagnóstico comportamental: um passo a passo. Em A. K. C. R. deFarias, F. N. Fonseca, \& L. B. Nery (Orgs.), Teoria e Formulação de Casos em Análise Comportamental Clínica (pp 23-48). Porto Alegre: Artmed.

Prust, Laísa Weber, \& Gomide, Paula Inez Cunha. (2007). Relação entre comportamento moral dos pais e dos filhos adolescentes. Estudos de Psicologia (Campinas), 24(1), 53-60. https:// dx.doi.org/10.1590/S0103-166X2007000100006 Ryle, G. (2009). The concept of mind. Routledge. Originalmente publicado em 1949.

Sampaio, I. T. A., \& Gomide, P. I. C. (2007). Inventário de estilos parentais (IEP)-Gomide (2006) percurso de padronização e normatização. Psicologia Argumento, 25(48), 15-26.

Sabbag, G. M., \& Bolsoni-Silva, A. T. (2011). The relation between social educative skills and maternal educative practices with adolescent behavior problems. Estudos e Pesquisas em Psicologia, 11(2), 423-441.

Sabbag, G. M., \& Bolsoni-Silva, A. T. (2015). Interações entre mães e adolescentes e os problemas de comportamento. Arquivos Brasileiros de Psicologia, 67(1), 68-83.

Skinner, B. F. (1945). The operational analysis of psychological terms. Psychological review, 52(5), 270-277. https://doi.org/10.1037/h0062535.

Skinner, B. F. (1991). Questões recentes em Análise Comportamental (A. L. Neri, trad.). Campinas: Papirus. (Obra originalmente publicada em 1989).

Skinner, B.F. (2000). Ciência e comportamento Humano. Tradução de J. C. Todorov e R. Azzi. São Paulo: Martins Fontes. (Trabalho original publicado em 1953).

Skinner, B. F. (2006). Sobre o behaviorismo (Tradução de M. da P. Villalobos). São Paulo: Cultrix. (Trabalho original publicado em 1974) Smith, N. W. (2007). Events and constructs. The 
Psychological Record, 57(2), 169-186. https:// doi.org/10.1007/BF03395570

Starling, R. R. (2004). Produção de Conhecimento e ciência natural - tudo o que é sólido pode se desmanchar no ar. In Brandão, M.Z. \& cols. (orgs.). Sobre Comportamento e Cognição. Vol. 14, (84-119). Santo André: Esetec

Strapasson, B. A., Carrara, K., \& Júnior, J. L. (2007). Conseqüências da interpretação funcional de termos psicológicos. Revista Brasileira de Terapia Comportamental e Cognitiva, 9(2), 227-239. DOI: https://doi.org/10.31505/rbtcc. v9i2.196

Veloso, R. J. M. D., Tonet, B., \& Dittrich, A. (2018). Contribuições de BF Skinner para a interpretação comportamental de termos cognitivos. Acta Comportamentalia, 26(3), 363-378.

\section{Informações do Artigo}

Histórico do artigo:

Submetido em: 17/06/2020

Primeira decisão editorial: 13/07/2020

Aceito em: 12/08/2020

Editora associada: Alessandra Turini Bolsoni-Silva 